\title{
NATIONAL PHYSICS OLYMPIADS FROM THE POINT OF VIEW OF PARTICIPANTS AND PHYSICS TEACHERS
}

\author{
Ludmila Belogrudova \\ University of Latvia, Latvia \\ Inese Dudareva \\ University of Latvia, Latvia \\ Vyacheslavs Kashcheyevs \\ University of Latvia, Latvia \\ Arnis Voitkans \\ University of Latvia, Latvia
}

\begin{abstract}
The development of student's interests and skills is strategically important to foster their career choice in the field of science, technology and engineering, which is one of the goals of Latvia's National Development Plan for 2021-2027. Physics Olympiads can be used as one of the enrichment measures to supplement formal school teaching in raising student motivation and developing their skills and talents. We explore directions in which the existing system of Physics Olympiads can be improved, with the goals of reaching a wider audience of teachers and students and achieving further integration with the learning processes in schools. We have conducted a survey of physics teachers $\left(N_{T}=188\right)$, and participants $\left(N_{P}=486\right)$ of the second (county) stage of Latvian Physics Olympiad in January 2020. The aim of the survey was to find out: 1) What motivates students to participate and teachers to encourage participation in Physics Olympiads? 2) What resources are used for training? 3) What further support would students and teachers need for training for the Olympics? Based on the results of the survey, we propose specific measures to support teachers and students in their engagement with Physics Olympiads, report on the implementation progress, and give an outlook for the future. Keywords: gifted education, Latvian Physics Olympiads, motivation, participants, physics teachers, supporting measures.
\end{abstract}

\section{Introduction}

According to the forecasts of the Ministry of Economics, by 2027 a significant shortage of highly qualified specialists in the field of science, technology, engineering and mathematics - of STEM for short is expected (Ministry of Economics Republic of Latvia, 2020) in Latvia. Qualitative implementation of the new curriculum, emphasizing the development of STEM 
skills, is defined in the Latvian National Development Plan for 2021-2027 as one of the indicators of quality education for the formation of a knowledge-based society (Cross-Sectoral Coordination Centre Republic of Latvia, 2020). The issue of how to engage young people in the field of STEM is relevant not only in Latvia - according to European Commission strategy for smart, sustainable and inclusive growth, at national level, Member States will need to ensure a sufficient supply of science, maths and engineering graduates (European Commission, 2020).

Student competitions in the field of STEM and Physics Olympiads particularly are considered to be a potent enrichment measure for developing student's problem-solving skills and fostering later career choice (Balta \& Asikainen, 2019; Campbell \& Walberg, 2011; Petersen \& Wulff, 2017; Friege \& Lind, 2001; Sahin, Gulacar, \& Stuessy, 2014).

Since 2012, the second (county) stage of the Latvian State Physics Olympiad has been taking place online on the Moodle-based platform (Dougiamas \& Taylor, 2003), gathering more than two thousand 9th-12th grade students every year. Participants are offered sets of tasks developed by the academic staff and students of the Department of Physics of the Faculty of Physics, Mathematics and Optometry of the University of Latvia. As this type of selection for the second (county) stage of the Olympiad has been done for the last nine years without changes, the time for evaluation is due. Therefore, two surveys were developed: one for physics teachers and one for participants of the Olympiad. The surveys were designed to address the following research questions: 1) What motivates students to participate and teachers to encourage participation in Physics Olympiads? 2) What resources are used for training? 3) What further support would students and teachers need for training for the Olympics?

\section{Physics Olympiads - Internationally and in Latvia}

The aims and tasks of the Latvian State Physics Olympiads (PhO) are to promote in-depth study of physics, research and experimental skills, to explore new talents in physics and to select Latvian state unit candidates for international competitions, as well as to promote students' interest in physics and encourage purposeful career choice (National Centre for Education Republic of Latvia, 2020). The Olympiad is organized and managed by the National Centre for Education Republic of Latvia, the University of Latvia Faculty of Physics, Mathematics and Optometry, the University of Latvia Information Technology Department and municipalities. The participants of the Olympics are 9th-12th grade students of general education schools.

The selection procedure for the International Physics Olympiad (IPhO) consists of four phases. The first stage is organized in schools. This stage is not 
mandatory and is not regulated, its organization is up to the physics teacher and the educational institution.

The second (county) stage, which is usually held in January, since 2012 is organized online. The PhO was the first to be organized online, over time it was followed by the organizers of Olympiads in other subjects: biology, chemistry, economics, geography, Latvian language, history, in the 2020/2021 school year the second phases of English language and philosophy were also planned online. Existing developments in the organization of online competitions allowed for the rapid adoption of the Latvian subject matter Olympiad selection process for the remote process, which was determined due to COVID spread restrictions.

The PhO course implemented in Moodle is in general accessible only to a restricted group of users - course participants, i.e. students. Users who want to access a Moodle site with PhO tasks must have an email account previously incorporated in a database and a password. PhO participants are divided into four groups corresponding to the student class and different tasks are assigned to each of them. Submitted solutions are evaluated automatically on a previously prepared set of tasks and participants receive the preliminary scored points by finishing $\mathrm{PhO}$. Participants can see the distribution of scores in their group.

An hour after the competition students can view the answers and solutions to all tasks and their mistakes in the online system. Then students can ask questions to the organizers in the forum about possible inaccuracies in the tasks and moderate their solutions. The Olympics results discussion forum is an important and valuable part of the Olympics, which promotes the involvement of participants, their physics teachers and task authors immersion in physics through debates and, as well as ensures the quality approbation of the Olympics tasks. If the organizers decide to correct an answer, then the reassessment can be done in a very short time for all 2000 and more participants.

During the last three years (2018-2020), 659 schools participated in the second stage of the Latvian State Physics Olympiad, which is $93.2 \%$ of the number of general education schools in Latvia (Central Statistical Bureau of Latvia, 2020). The number of participants varies slightly from year to year: from 1861 in 2012 to 2519 in 2016, it is around 5\% of the number of 9th-12th grade students in the country (Ministry of Education and Science Republic of Latvia [IZM], 2020).

According to the results of the second stage, around 100-120 most successful participants are invited to the third (national) stage, which takes place in March or April for two days at the University of Latvia. The winners of the third stage are 12-20 students who are nominated for participating in the Nordic-Baltic Physics Olympiad, which serves as the final selection stage for the Latvian IPhO team. 
The selection process of the teams and their preparation for the Olympiads differ from country to country, on average, the IPhO participating countries have 3.1 selection stages, average number of participants in the first stages among the countries ranges from classroom size to about half million in P.R.China (Petersen \& Wulff, 2017). In Latvia about $4 \%$ of the county stage participants are invited to the next stage, about $1 \%$ win prizes (which is one of the factors influencing school rankings), and only about $0.2 \%$ are selected for participation in the IPhO. But in some other countries this percentage is much lower: $0.00008 \%$ in the US, 0.00002\% in China (Campbell \& Walberg, 2011).

\section{Role of Motivation in Physics Olympiads}

Motivation is a main factor to successful learning and achievements, it is "a force that energizes, directs and maintains behaviour toward a goal" (Pintrich \& Schunk, 2002). Motivation is influenced by various factors: parenting, attitudes of teachers and peers, the results of the individual's own activities (Skujina, 2000). Motivation in relation to a subject influences career choice - most students make decisions about further studies during high school, and their career interests are affected most of all by their teachers, personal interests and family (Sahin, Gulacar, \& Stuessy, 2014).

Concepts related to motivation are: interest, need (for achievement, for affiliation, e.g. friendly relationships with other persons, for leadership), attitude (getting pleasure from activity) and aspirations (having a particular aim) (Clues \& Charlton, 2007). It is revealed that there is no significant difference in the attitude and motivation of students towards learning physics (Guido, 2013), and therefore, motivation and related concepts are used interchangeably in this article.

Because motivation is an extensive and complex issue, researchers and theorists have different views on motivation, two of which are - intrinsic motivation (preferred type of motivation), which may be defined as "studying for its own sake". In contrast, extrinsic motivation depends upon external factors (including test results and marks) (Clues \& Charlton, 2007). It is found that "intrinsic motivation and extrinsic incentives have positive impacts on solvers' task effort” (Liang, Wang, Wang, \& Xue, 2017).

Olympiads, as one of enrichment measurements used for teaching gifted children, provide good motivation and a sustainable environment for the development of students` talents (Liashenko, Khalezov, \& Arsalidou, 2017; Ushakov, 2000). Studies show that most often high school students participate in the competitions to get better in physics and because of interest in physics and challenging problems solving (Kolar, 2019; Friege \& Lind, 1999).

An international study of long-term effects of olympiads shows that the average intelligence of the winners of the physics olympiads is not above the 
average intelligence of the secondary school students. Rather, success is determined by an interest in physics and effort willingness (Friege \& Lind, 2001). Thus, identifying, maintaining, and increasing motivation is one of the most important preconditions to reach $\mathrm{PhO}$ main goals: promoting excellence in physics and career choices in the field of STEM for high school students.

\section{Methodology}

The research is based on the results of a survey of 188 physics teachers and 486 participants of the 70th Latvian Physics Olympiad county stage.

The survey of teachers was organized electronically using the contacts database of members of the Latvian Physics Teachers' Association and the list of education institutions available on the website of the Ministry of Education and Science (IZM, 2020). Participation in the survey was voluntary. Teachers' responses were registered from 15 to 24 January 2020. The aim of the survey was to find out the factors that influence why teachers do or do not encourage their students to participate in $\mathrm{PhO}$, to gather physics teachers' opinions on the process of organizing national $\mathrm{PhO}$, to understand what kind of support would be useful for teachers to prepare students for $\mathrm{PhO}$, as well as linking the above issues to teacher education, work experience and school type. All questions for teachers (except for general information about the respondent) were offered as open-ended questions.

The survey of the participants of the Olympiad was executed to find out 1) motivation to participate in the $\mathrm{PhO}$ (open-ended question); 2) resources used by students in preparation for the $\mathrm{PhO}$ (closed question); 3) support needed to improve preparing for the Olympics (closed question). The proposed questionnaire was very short to avoid participants` distraction from the Olympics. It was offered on the Olympics website on the day of the Olympics and was available to participants after logging in to the system. Participation in the survey was voluntary and did not affect participation in the Olympics.

The answers to open-ended questions in both surveys were grouped by content, creating categories further used for statistical analysis.

Margin of error for percentage points is calculated at 95\% confidence level taking into account the relevant population size $\mathrm{n}$.

\section{Olympiad Participants Survey Results}

The survey was addressed to 2352 participants of the Olympiad, 486 of them filled the form ( $20 \%$ of potential respondents). 
In analysis the effect of school type four types of schools were considered: basic schools (offer education up to 9th grade), secondary schools, gymnasiums/ state gymnasiums except for Riga (gymnasiums typically have more resources and more stringent student admission criteria) and state gymnasiums in Riga (the capital Riga is likely to attract more talent due to Latvia's centralized structure). Answers to the open question about motivation to participate in physics Olympiads, were grouped into nine categories shown in Table 1:

Table 1 Motivation of Students for Participation in Physics Olympiad

\begin{tabular}{|c|l|}
\hline $\mathbf{\%}$ & \multicolumn{1}{|c|}{ Participants answers } \\
\hline $52 \%$ & to test and prove one's knowledge and capabilities in physics \\
\hline $20 \%$ & to get new experience and further improve in physics \\
\hline $16 \%$ & being interested in physics or liking the subject \\
\hline $11 \%$ & to prepare for future study \\
\hline $7 \%$ & to spend time interestingly, to get relief from lessons \\
\hline $6 \%$ & to be challenged by solving complex and hard problems \\
\hline $4 \%$ & encouragement from teacher/parents \\
\hline $3 \%$ & no motivation/difficult to answer \\
\hline $2 \%$ & to defend the school's honour/to earn an award \\
\hline
\end{tabular}

The total exceeds $100 \%$ because some respondents mentioned several kinds of motivation.

The distribution of answers is not significantly correlated with the class group and the school type.

In order to find out what kind of resources the participants of the Olympiad use for preparation, a closed-ended question with five answer options was offered, from which one or more could be chosen. The choices of the participants are summarized in Table 2.

Table 2 Resources and Actions Used by Participants for Training

\begin{tabular}{|c|l|}
\hline $\mathbf{\%}$ & \multicolumn{1}{|c|}{ Participant's answers } \\
\hline $55 \%$ & solving online tasks of previous years' Olympics on the website edu.lu.lv \\
\hline $49 \%$ & reading theory and solving problems from books and taskbooks \\
\hline $40 \%$ & attending additional physics classes/consultations at school \\
\hline $40 \%$ & solving additional tasks offered by the teacher \\
\hline $22 \%$ & not specially preparing anything \\
\hline
\end{tabular}

The total exceeds 100\% because many respondents chose several answer options.

It seems that the 9th grade students attend physics consultations at school more often $(53 \% \pm 9 \%, n=133$ vs. $33 \% \pm 10 \%, n=86$ in 12 th grade). To prepare for the Olympics, a teacher's consultations are used more frequently by basic school 
SOCIETY. INTEGRATION. EDUCATION

Proceedings of the International Scientific Conference. Volume II, May $28^{\text {th }}-29^{\text {th }}$, 2021. 84-95

students $(51 \% \pm 17 \% ; \mathrm{n}=35)$ and least often by Riga state gymnasiums students (23\% $\pm 7 \% ; n=127)$.

When asked what kind of support would be needed to better prepare for the Olympics, the most popular answers are training materials with typical problemsolving techniques and more detailed explanations of solutions on the Olympiad website (Table 3).

Table 3 What Kind of Support Would Be Needed to Better Prepare for the PhO

\begin{tabular}{|c|l|}
\hline $\mathbf{\%}$ & \multicolumn{1}{|c|}{ Participant's answers } \\
\hline $52 \%$ & training material, which would clarify the typical problem-solving techniques \\
\hline $44 \%$ & $\begin{array}{l}\text { more detailed explanations of the solutions of the previous years' Olympics tasks } \\
\text { on the website edu.lu.lv }\end{array}$ \\
\hline $35 \%$ & $\begin{array}{l}\text { there is enough support, but it 's hard to find the time and motivation to do anything } \\
\text { extra }\end{array}$ \\
\hline $23 \%$ & special classes in physics outside school \\
\hline $21 \%$ & $\begin{array}{l}\text { if there were more students in the class preparing for the Physics Olympiad to be } \\
\text { able to prepare together }\end{array}$ \\
\hline $21 \%$ & more efficient learning process at school physics classes \\
\hline $19 \%$ & more individual consultations are available at the school with a physics teacher \\
\hline
\end{tabular}

The total exceeds $100 \%$ because many respondents chose several answer options

These results do not differ significantly by class group and school type.

\section{Physics Teachers Survey Results}

The survey was fulfilled by 188 teachers, of whom $9 \%$ are new teachers who have been working at the school for less than two years, 26\% are teachers with 310years experience, $20 \%$ with 11-20years experience and almost half - $45 \%$ with more than 20years experience.

This distribution is consistent with the general demographics of teachers in Latvia - according to the statistics of the Ministry of Education, the proportion of new teachers has significantly decreased over the last twenty years and the proportion of old teachers has almost doubled. $44 \%$ of respondents teach only physics, the rest teach physics and one or two other subjects, most often mathematics (35\%), computer science (17.5\%), chemistry (7.5\%), and biology (5\%).

Within the group of the teachers who have entered the school in recent years, only about a third have initially studied to be physics teachers, the rest are either teachers of other subjects or specialists in other fields who have later acquired the right to teach physics (among teachers with more than 20 years of experience $70 \%$ have initially studied to be physics teachers). 
The majority of teachers, $77 \%$, have indicated that in the last three years their students have participated in the second (county) stage of the PhO. Among the teachers whose students have not participated in the Olympiads in the last three years, more than a half are teachers with little work experience. When asked why students are not encouraged to participate in $\mathrm{PhO}$, teachers with more experience mention students' poor level of knowledge and motivation, lack of time, as well as the fact that the teacher himself has difficulties in solving the tasks of the Olympics.

The highest proportion of teachers whose students have participated in $\mathrm{PhO}$ in the last three years is among those who only teach physics $(88 \% \pm 7 \%$; $n=83$ versus $67 \% \pm 9 \% n=105$ for teachers of two or more subjects). There are no significant differences between teachers who initially studied to be physics teachers and those who came from other fields or retrained as physics teachers.

The answers to the open-ended question about support for teachers and their students to help them prepare for and participate in the Physics Olympiads are summarized in Table 4.

As limitations of the online physics Olympiad phase, teachers point to the complexity of the tasks offered (20\%) and their inconsistency with the school curriculum (10\%), the fact that the system does not give an impression about how participants thinking (9\%) and points may be lost due to arithmetical errors (7\%), inaccurate task formulations (5\%), inconvenient registration system and access to training tasks (3\%). It should be noted that $11 \%$ of teachers indicate that they do not see any drawbacks in the organization of this stage. Regarding the limitations of the third stage, teachers mention that the number of invited participants is too small, that the tasks are too complex, that both rounds (theoretical and experimental) take place in one day, that there is no organized moderation and results discussion process.

Table 4 What Kind of Support Would Be Needed to Better Prepare for the PhO

\begin{tabular}{|c|l|}
\hline $\mathbf{\%}$ & \multicolumn{1}{|c|}{ Teachers' answers } \\
\hline $26 \%$ & training material, which would clarify the typical problem-solving techniques \\
\hline $16 \%$ & seminars for teachers in problem solving methodology \\
\hline $11 \%$ & more individual consultations to be charged at the salary \\
\hline $7 \%$ & solutions to previous years' Olympics tasks in PDF or other printed-out format \\
\hline $5 \%$ & special classes in physics outside school \\
\hline $5 \%$ & to include in the Olympiad more problems that are feasible for students \\
\hline $5 \%$ & Olympics program with intended content \\
\hline $4 \%$ & there is enough support \\
\hline $3 \%$ & if the Olympiads of different subjects did not follow one another \\
\hline
\end{tabular}


SOCIETY. INTEGRATION. EDUCATION

Proceedings of the International Scientific Conference. Volume II, May $28^{\text {th }}-29^{\text {th }}$, 2021. 84-95

Table 5 Why to Encourage Students to Participate in Physics Olympiads

\begin{tabular}{|c|l|}
\hline $\mathbf{\%}$ & \multicolumn{1}{|c|}{ Teachers' answers } \\
\hline $25 \%$ & opportunity for students to test their knowledge and gain proof of their abilities \\
\hline $24 \%$ & students' interest in physics and the opportunity to realize their potential \\
\hline $21 \%$ & students' growth during preparation for and participation in the Olympics \\
\hline $6 \%$ & success in the Olympics can affect university enrollment \\
\hline $5 \%$ & students have the opportunity to gain new experiences \\
\hline $5 \%$ & raising the school rating \\
\hline $4 \%$ & prove that I am a good teacher \\
\hline $4 \%$ & interesting problems \\
\hline $3 \%$ & encouragement from the school administration \\
\hline $3 \%$ & prize from the municipality \\
\hline
\end{tabular}

Teachers indicate that in physics olympiads they like interesting tasks (19\%), the opportunity for students to test and prove themselves, train and learn (15\%), online format (13\%), the opportunity to receive quick feedback (10\%).

This is also reflected in the answer to the question of teachers' motivation to encourage students to participate in physics olympiads (Table 5).

\section{Conclusions and Discussion}

Our results show that students participate in the $\mathrm{PhO}$ to test and prove their knowledge and capabilities in physics (52\%), to get new experience and further improve in physics (20\%), because they are interested in physics (16\%) and to prepare for future study (11\%). These factors are largely consistent with other studies (Kolar, 2019; Friege \& Lind, 1999). External motivational incentives, such as awards, play a minor role. Primary (why participating for the first time) and secondary (why participating repeatedly) factors were not considered separately in the study. Also, the possible demotivating factors and how participation in the Olympics influenced the motivation to study physics for participants who did not have high success were not studied.

The revealed views of the participants in the Olympics and their physics teachers on why to participate in the Physics Olympiads largely coincide. Teachers encourage students to participate in physics olympiads, as the most important factors for students noting possibility to test their knowledge and gain proof of their abilities, to realize their potential, interest in physics and improving skills and knowledge during preparation for and participation in the Olympics.

Answering the research question about resources used for training it was found that more than half of the students solve online tasks of previous years' Olympics using the online platform edu.lu.lv (55\%), 49\% read theory and solve 
problems from books, $40 \%$ attending additional physics classes/consultations at school. According to survey results, participants from younger class groups more often attend physics consultations at school.

Answering about further support needed for training for the Olympics, both students and teachers highlight the need for training material, which would clarify the typical problem-solving techniques. As a second important possible support, students point to the need for more detailed explanations of the solutions of the previous years' Olympics tasks on the website (44\%). About a third of students admit that there is enough support, but it is a lack of time and motivation to prepare for the Olympics. The second most popular response from physics teachers to the needed support is necessity for seminars in problem solving methodology.

\section{Outlook}

Further research is required to find out how the motivation to participate in physics olympiads differs between those who do it for the first time and those who do it again. This would help not only to attract new participants to the PhO, but also to maintain motivation and interest in physics for those who have ever participated in the PhO. For these reasons possible demotivating factors and the impact of Olympiad participation on underperforming students should also be explored.

In 2020, in cooperation with the National Centre for Education Republic of Latvia, a physics Olympiads` problem taskbook of was written. It includes the tasks of the second and third stages of the 2017-2020 Physics Olympiad for the last four years with prompting questions and detailed explanations of the solutions. Over time, it is planned to supplement the online platform edu.lu.lv with more detailed explanations of tasks, thus responding to the need of teachers and students for detailed explanations of the solutions to the Olympics problems.

Based on the results of the survey reported here, a seminar for teachers was organized on the methodology of solving the Olympics tasks in mechanics, as well as appropriate support materials were developed in the course of years 2020, with encouraging early feedback from teachers.

\section{References}

Balta, N., Asikainen, M.A. (2019). A comparison of Olympians' and regular students' approaches and successes in solving counterintuitive dynamics problems. International Journal of Science Education, 41 (12), 1644-1666. DOI: 0.1080/09500693.2019.1624990

Campbell, J.R., Walberg, H.J. (2011). Olympiad studies: Competitions provide alternatives to developing talents that serve national interests Roeper Review, 33 (1), 8-17. DOI: 10.1080/02783193.2011.530202 
Central Statistical Bureau of Latvia. (2020). Education institutions and enrolment. Retrieved from: https://data1.csb.gov.lv/pxweb/lv/sociala/sociala_izgl_visparigi/IZG010.px/table/t ableViewLayout1/

Clues, D., Charlton, M. (Ed.) (2007). Teaching, training \& learning. Great Britain, Business Education Publishers.

Cross-Sectoral Coordination Centre Republic of Latvia. (2020). National Development Plan for 2021-2027. Retrieved from: https://www.pkc.gov.lv/lv/nap2027

Dougiamas, M., Taylor, P. (2003). Moodle: Using Learning Communities to Create an Open Source Course Management System. World Conference on Educational Multimedia, Hypermedia \& Telecommunications, 171-178, USA. Retrieved from: https://research.moodle.org/33/

European Commission. (2020). A strategy for smart, sustainable and inclusive growth. Retrieved from: https://eur-lex.europa.eu/legal-content/EN/TXT/PDF/?uri=CELEX: 52010DC2020\&from $=$ en

Friege, G, Lind, G. (1999). Four Steps To The IPhO. The German Selection Process. Physics Competitions, 1(1), 45-54.

Friege, G, Lind, G. (2001). What characterizes participants at the olympiad besides their physics problem solving abilities? Some results from a retrospective survey among former German Physics Olympiad participants. Physics Competitions, 3(2), 7-15.

Guido, R.M. (2013). Attitude and Motivation towards Learning Physics International Journal of Engineering Research and Technology, 2 (11). Retrieved from: https://www.researchgate.net/publication/325008799_Attitude_and_Motivation_toward s_Learning_Physics

Kolar, K. (2019). Sources of motivation of high school students for participation in physics competitions. Journal of Physics: Conference Series 1286 012067, DOI: 10.1088/17426596/1286/1/012067

Liang, H., Wang, M., Wang, J., Xue, Y. (2017). How Intrinsic Motivation and Extrinsic Incentives Affect Task Effort in Crowdsourcing Contests: A Mediated Moderation Model, Computers in Human Behavior, DOI: 10.1016/j.chb. 2017.11.040

Liashenko, A.K., Khalezov, E.A., Arsalidou, M. (2017). Methods for identifying cognitively gifted children. Psychology, Journal of the Higher School of Economics, 14 (2), 207-218. DOI: 10.17323/1813-8918-2017-2-207-218

Ministry of Economics Republic of Latvia. (2020). Informative Report on Medium and Longterm Labour Market Forecasts. Retrieved from: https://www.em.gov.lv/lv/videja-unilgtermina-darba-tirgus-prognozes

Ministry of Education and Science Republic of Latvia. (2020). Official statistics on general education. Retrieved from: https://www.izm.gov.lv/lv/oficiala-statistika-par-visparejoizglitibu

National Centre for Education Republic of Latvia. (2020). Fizikas valsts 71.olimpiades norises kartiba. Retrieved from: https://www.visc.gov.lv/en/node/29

Petersen, S., Wulff, P. (2017). The German Physics Olympiad - Identifying and inspiring talents. European Journal of Physics, 38 (3). DOI: 10.1088/1361-6404/aa538f

Pintrich, P.R., \& Schunk, D.H. (2002). Motivation in Education. Englewood Cliffs, NJ: Prentice Hall. 
Sahin, A., Gulacar, O., \& Stuessy, C. (2014). High School Students’ Perceptions of the Effects of International Science Olympiad on Their STEM Career Aspirations and Twenty-First Century Skill Development. Research in Science Education, 45(6), 785-805. DOI: 10.1007/s11165-014-9439-5

Skujina, V. (Ed.) (2000). Pedagogijas terminu skaidrojosa. Riga, Zvaigzne ABC.

Ushakov, D.V. (Ed.). (2000). Psikhologiya odarennosti. Ot teorii k praktike. Moscow: PER SE. 